\title{
Establishment of Risk Evaluation Index System for Third Party Payment in Internet Finance
}

\author{
Wenfang Cao \\ Wuhan Polytechnic, Wuhan, 430074, China \\ 1377272139@qq.com
}

Keywords: internet finance; third party payment; risk evaluation; index system

\begin{abstract}
Internet and financial business integration, gave birth to the internet finance, improve the efficiency of the allocation of financial resources, third-party payment has the advantage in solving the financial flow of internet finance, but there are also great risks. Risk assessment is an effective means to resolve risks. The establishment of index system is the basic work of evaluation. Based on the third-party payment process, this paper constructs the evaluation index system structure model by using qualitative analysis method, uses the quantitative analysis method to determine the weight of the index system, and presents a complete evaluation index system consisting of the index name and weight. The research results of this article enriched the internet financial evaluation theory and also provided a reference for improving the internet financial regulatory system.
\end{abstract}

\section{Introduction}

Internet finance is a new type of financial business model of traditional financial institutions and internet companies that use the internet and information and communication technologies to realize financial intermediation, payment, investment and information intermediary services. Internet finance Based on the internet, the financial business has the characteristics of "transparency, high participation, good cooperation, low intermediate cost and convenient operation". Promoting the healthy development of internet finance is conducive to improving the quality and efficiency of financial services, deepening financial reform, promoting financial innovation and development, expanding the opening up of the financial industry, building a multi-level financial system and promoting economic development. Third-party payment is an independent organization with certain strength and reputation guarantee. It adopts the way of signing contracts with banks and uses the network transaction support platform to provide the network payment mode that interfaces with the bank's payment and settlement system [1,2]. The third-party payment, as the main network transaction means and credit intermediary at present, establishes the connection with the merchant and the bank through the network and has the function of third-party supervision and technical support.

Third-party payments have an advantage in resolving the financial flows of internet finance. However, due to the imperfect laws and regulations and many complicated factors in the network environment, third-party payment is accompanied by many risks, how to analyze and evaluate the risks and then take control measures to minimize the risks, which are urgent problems in the development of internet finance problem. According to the idea of risk management, firstly, construct the risk evaluation index system; then, evaluate the risk; finally, put forward the risk control measures in order to ensure the effectiveness of risk control and ensure the healthy development of the third-party payment under internet finance. The content of this paper is the basic work of risk management, which provides a support for the third-party payment risk assessment of internet finance.

\section{Process on Third Party Payment}

The third party payment the general mode of operation: the buyer after the purchase of goods, the use of third-party platform to provide payment for the purchase of goods, third-party receipt of the 
deposit on behalf of the deposit, notify the seller of money credited into account, requiring businesses to ship; After arriving at the goods, verifying the goods and confirming, the third party is notified; the third party transfers the money to the seller's account. The essence of this transaction completion process is an intermediary service that provides settlement credit guarantee. Third-party payment mode so that businesses can not see the customer's payment card information, but also can avoid the payment card information in the network several times public transmission caused by theft of payment card information, third-party payment process shown in Fig. 1.

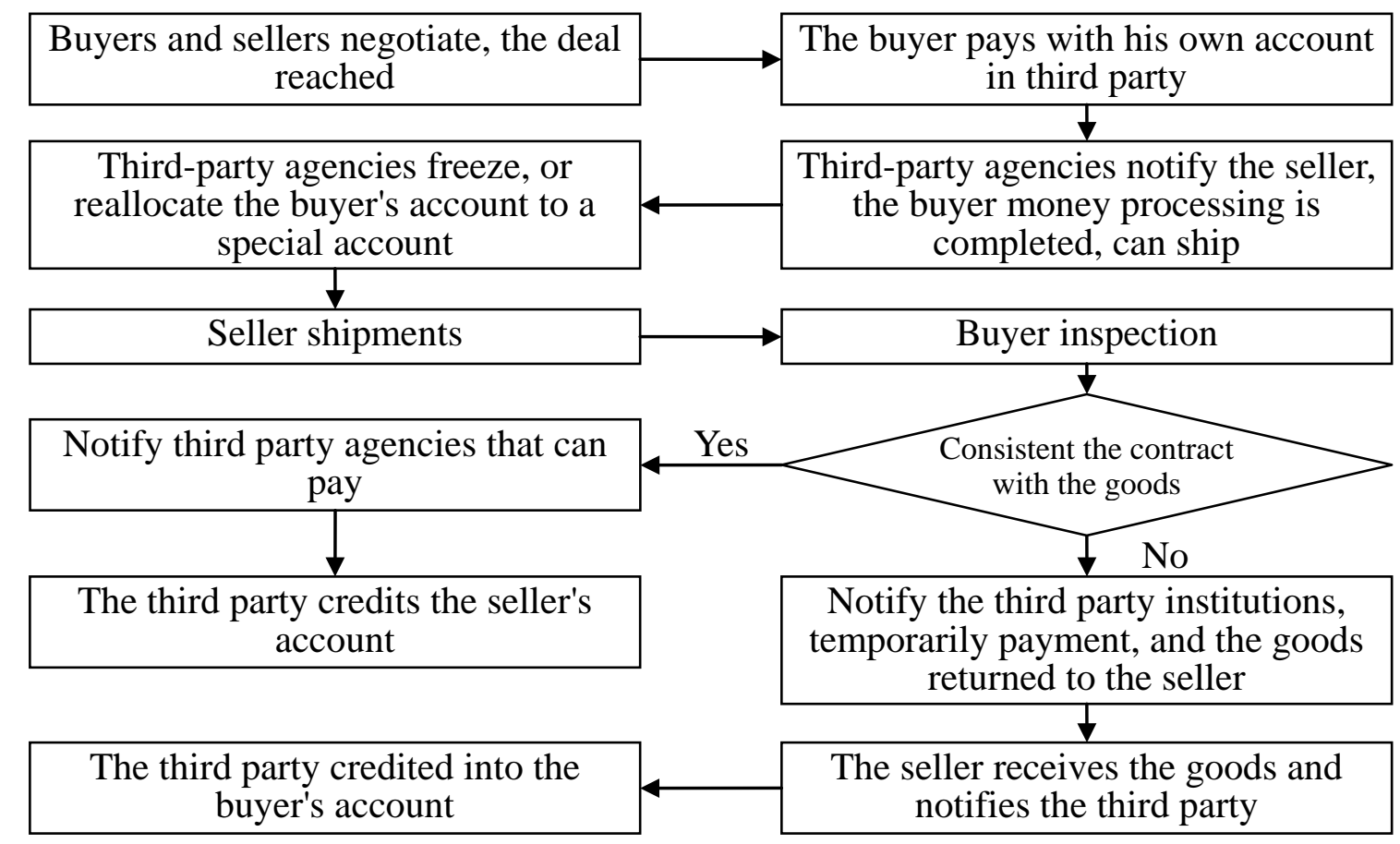

Fig. 1. Process on third party payment

Third party payment listed the following advantages: Third-party payment platform with the cooperation of many banks to facilitate online transactions, for businesses, do not have to install the authentication software of each bank, simplifying the cost and operation; third-party payment platform as an intermediary side, to promote businesses and banks to reduce business operating costs; banks directly use third-party service system to provide services to help banks save gateway development costs; third-party payment platform to provide value-added services to help businesses solve real-time transaction queries and trading system analysis, To provide convenient and timely refund and stop payment services; third-party payment platform records the transaction information of both parties in detail to prevent the parties to the transaction may be deny the transaction, as well as the follow-up transactions may provide evidence of disputes.

Third-party payment is widely used. However, due to the incomplete laws and policies of our country and the failure to establish a national credit system, the security of third-party payment can not be well guaranteed and faces many challenges. There are still many deficiencies, mainly as follows: Not suitable for B2B; buyers and sellers often appear in the transaction disputes, the relevant departments to obtain evidence difficult; payment platform is flawed, there will inevitably be man-made situations. In addition, there are some third-party payment platform security vulnerabilities, but also need to further improve and improve.

\section{Structure Model of Evaluation Index System}

The development of scientific evaluation index system is the basic work of systematic evaluation. Using a single indicator or a few indicators of a simple combination of evaluation has a certain one-sidedness and subjectivity. System refers to a certain range or similar things, in accordance with a certain order and internal linkages of the overall composition. Only a scientific and reasonable evaluation index system, it is possible to draw scientific and fair evaluation conclusion. 
In the process of constructing index system, we must first follow the general principles of index system construction, but also pay attention to the necessity of the elements in the index system. Without loss of comprehensiveness, we should minimize the number of indicators in the system and pay attention to the evaluation of index system Function, promotion function and decision-making function. The evaluation index system is usually expressed in a hierarchical structure. The highest level represents the overall goal of the system. The middle layer represents the middle part to achieve the overall goal. The lowest level represents the measures to be selected for achieving the goal. Referring to the relevant literature [3,5], this article builds the Internet finance third-party payment risk evaluation index architecture model shown in Fig. 2.

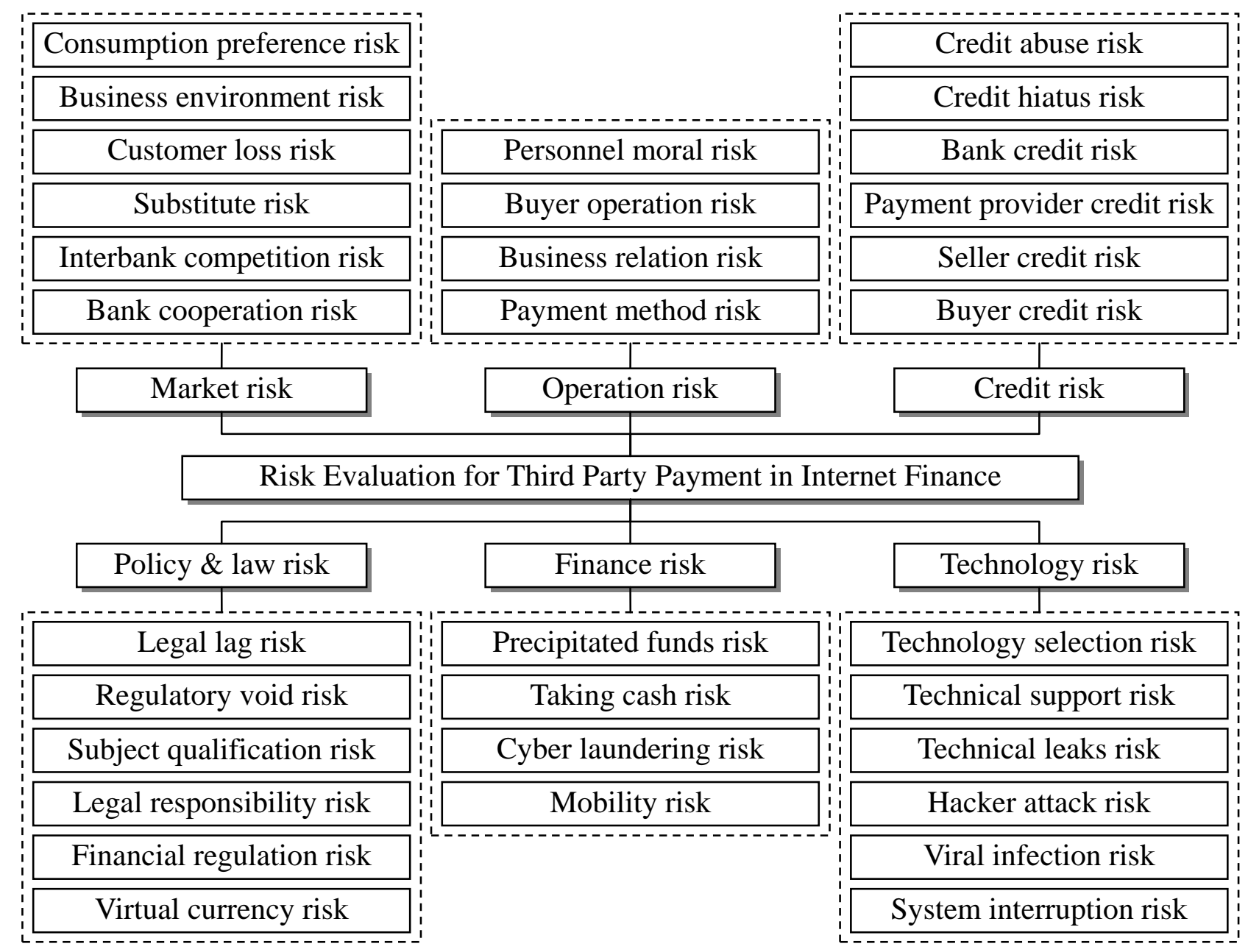

Fig. 2. Structure model on risk evaluation index system for third party payment in internet finance

In the evaluation index system shown in Fig. 2, the third-party payment risks of internet finance are summarized into six categories: The first category is Market risk. Third-party payment enterprises are faced with market risk such as fierce competition, narrow profit margins and recession of the industry. The second category is Operational Risk. Incomplete or problematic internal operational processes, personnel, systems or external events, resulting in the risk of direct or indirect loss; the third category: Credit risk. The risk that is third-party payment providers not fully performs their obligations at contract expiration date. Internet finance has significant virtuality, data validity and authenticity are not enough, and credit risk also becomes a risk that must be taken seriously. The fourth category is policy and law risk. Third-party payment development started late, the relative laws and regulations are lagging behind, and the regulatory system is still not perfect. Legal weakness, unclear positioning of regulatory responsibilities, deterring consumers' normal rights protection. The fifth category is financial risks. As an important part of internet finance, third-party payment, though it belongs to non-financial institutions, has provided services that involve the financial sector, including financial transactions such as payment and settlement and 
settlement of capital deposits, and related financial risks similar to those of financial institutions. Six categories: technical risk. Mainly reflect in the bank settlement interface system, the payment service provider payment system and the seller's terminal system and so on.

\section{Mathematical Model on Weight Calculation for Index System}

Weights represent the quantitative distribution of the degree of importance of the appraisers from different aspects during the appraisal process, and discriminate the roles of appraisal indicators in the overall appraisal. When using index system for comprehensive evaluation, the relative importance of the different indicators, the relative importance of such indicators between the size of the weight or weight coefficient. Different weights will lead to different evaluation results, so determining the reasonable weight is one of the important issues in constructing index system. There are many ways to calculate the weight of indicator system, this article uses KLEE method.

KLEE is a scientific method of subjective judgment expressed in quantitative form. It is a combination of quantitative and qualitative methods. It uses matrix form to represent the evaluation value of each alternative scheme, and calculates the weighted sum of each program evaluation value, and then through analysis and comparison, determines the weight and the optimal program. The mathematical model is as follows:

There are $n$ evaluation indicators, $R_{i}(i=n, n-1, \cdots, 2,1)$ indicating that the evaluation indicators from top to bottom each other after comparing the importance of each level, that is the importance. $P_{i}$, it means that the assessment value of $i$ indicator in the project. Since the last nth indicator has no other indicators compared with it, there is no existence,

$$
\left\{\begin{array}{l}
P_{n}=1 \\
P_{i-1}=R_{i-1} \times P_{i} \quad(i=n, n-1, \cdots, 2)
\end{array}\right.
$$

After $P_{i}$ is normalized, it is the weight of the calculated index value, and the formula is:

$$
w_{i}=P_{i} /\left[\sum_{i=1}^{n} P_{i}\right]
$$

\section{Results on Weight Calculation for Index System}

For the evaluation index system shown in Figure 1, the weight of each level two indicator to the level one indicator and the weight of the level one indicator to the total evaluation target should be calculated separately. Limited by the length of the article, only the weights of the target of a first-class indicator for the total evaluation as an example illustrate. The calculation process and results are shown in Table 1.

Table 1. Weight calculation results on first level evaluation index

\begin{tabular}{ccccc}
\hline First level indicator & Number & $R_{i}$ & $P_{i}$ & $w_{i}$ \\
\hline Market risk & 1 & 1.2 & 1.034 & 0.1627 \\
Operation risk & 2 & 0.8 & 0.862 & 0.1357 \\
Credit risk & 3 & 1.1 & 1.078 & 0.1697 \\
Policy \& law risk & 4 & 0.7 & 0.980 & 0.1542 \\
Finance risk & 5 & 1.4 & 1.400 & 0.2203 \\
Technology risk & 6 & $/$ & 1.000 & 0.1574 \\
\hline Total & & & 6.354 & 1.0000 \\
\hline
\end{tabular}

For each level of indicators, the ranking by weight is "financial risk, credit risk, market risk, technical risk, policy legal risk, operational risk, and operational risk."Financial risk" has the heaviest weight, so it must pay attention to the financial risk paid by the third party. Table 2 shows the weight calculation results of the first-level indicators for each second-level indicator. 
Table 2. Weight calculation results on second evaluation index

\begin{tabular}{cc|cc}
\hline Index Name & Weight & Index Name & Weight \\
\hline Bank cooperation risk & 0.2421 & Legal lag risk & 0.1673 \\
Interbank competition risk & 0.1714 & Regulatory void risk & 0.2212 \\
Substitute risk & 0.1328 & Subject qualification risk & 0.1235 \\
Customer loss risk & 0.2076 & Legal responsibility risk & 0.1421 \\
Business environment risk & 0.1425 & Financial regulation risk & 0.1916 \\
Consumption preference risk & 0.1036 & Virtual currency risk & 0.1543 \\
\hline Payment method risk & 0.2209 & Precipitated funds risk & 0.2164 \\
Business relation risk & 0.2710 & Taking cash risk & 0.2533 \\
Buyer operation risk & 0.1767 & Cyber laundering risk & 0.2498 \\
Personnel moral risk & 0.3314 & Mobility risk & 0.2805 \\
\hline Buyer credit risk & 0.1827 & Technology selection risk & 0.2326 \\
Seller credit risk & 0.1242 & Technical support risk & 0.1836 \\
Payment provider credit risk & 0.2426 & Technical leaks risk & 0.0981 \\
Bank credit risk & 0.1518 & Hacker attack risk & 0.2114 \\
Credit hiatus risk & 0.0827 & Viral infection risk & 0.1201 \\
Credit abuse risk & 0.2160 & System interruption risk & 0.1542 \\
\hline
\end{tabular}

\section{Conclusion}

Third-party payment services, payment forms, payment tools and market competition, etc. are constantly expanding, rapid development accompanied by many risks, management is not standardized, unsynchronized technology updates, security measures are not in place and user information Leakage, etc., affecting the stability and security of the entire Internet financial system, thereby affecting the stability of social and economic life. Therefore, it is necessary to analyze and evaluate the possible risks that the third party pays for, put forward feasible countermeasures against risks, maintain a sound economic environment and safeguard financial security.

\section{References}

[1] Worry free payment network, "The concept, characteristics and advantages of the third party payment platform," http://www.wyzhifu.com/yjwendang/910.html, 2017-12-17.

[2] Information management network, "The characteristics and advantages and disadvantages of the third party payment," http://www.cnitpm.com/pm/11857.html, 2017-12-17.

[3] Y. M. Nie, H. L. Wu, "Research on the risk evaluation system of the three party payment under the Internet financial background," Private science and technology, vol. 23, no. 9, pp. 187-188, 2017.

[4] H. F. Gu, L. X. Yang, "Risk Evaluating of China's Third-party Mobile Payment: Model Construction and Empirical Analysis," Financial Regulation Research, vol. 5, no. 5, pp. 1-21, 2017.

[5] L. Y. Wang, Y. Shi, "Risk mechanism and risk evaluation of internet finance: a case study of P2P net loan," Journal of Southeast University (Philosophy and Social Science), vol. 18, no. 2, pp. 103-112, 2016. 